\title{
Rapid, noninflammatory and PS-dependent phagocytic clearance of necrotic cells
}

\author{
UA Hirt ${ }^{1,2}$ and M Leist ${ }^{\star, 1,3}$ \\ 1 Faculty of Biology, University of Konstanz, X911, D-78457 Konstanz, Germany \\ 2 Apogenix Biotechnology AG, Im Neuenheimer Feld 581, 69120 Heidelberg, \\ Germany \\ ${ }^{3}$ H. Lundbeck A/S, Ottiliavej 9, DK-2500 Valby, Denmark \\ * Corresponding author: M Leist, Lundbeck A/S, Ottiliavej 9, DK-2500 Valby, \\ Kobenhavn, Denmark. Tel: + 45-3630-1311-3360; Fax: +45-3630-3747; \\ E-mail: male@ @undbeck.com
}

Received 20.12.02; revised 24.4.03; accepted 06.5.03 Edited by G Melino

\section{Abstract \\ In pathological situations, different modes of cell death are observed, and information on the role and uptake of nonapoptotic corpses is scarce. Here, we modeled two distinct forms of death in human Jurkat $T$ cells treated with staurosporine: classical apoptosis under normal culture conditions and programmed death with necrotic morphology under ATP-depleting conditions (necPCD). When offered to phagocytes, both types of cell corpses (but not heat-killed unscheduled necrotic cells) reduced the release of the proinflammatory cytokine TNF from the macrophages. The necPCD cells were efficiently engulfed by macrophages and microglia, and from mixtures of necPCD and apoptotic cells macrophages preferentially engulfed the necrotic cells. Using a newly developed assay, we demonstrated that phosphati- dylserine is translocated to the surface of such necrotic cells. We demonstrate that this can occur independently of calcium signals, and that surface phosphatidylserine is essential for the uptake of necrotic cells by both human macrophages and murine microglia. \\ Cell Death and Differentiation (2003) 10, 1156-1164. doi:10.1038/ sj.cdd. 4401286}

Keywords: phagocytosis; apoptosis; necrosis; phosphatidylserine; inflammation

Abbreviations: PCD, programmed cell death; PS, phosphatidylserine; PC, phosphatidylcholine; PSR, PS-receptor; STS, staurosporine; HMDM, human monocyte-derived macrophages; PFA, paraformaldehyde; MACS, magnetic cell sorting

\section{Introduction}

Phagocytosis is a key feature of programmed cell death with vast implications for tissue integrity and tissue turnover. ${ }^{1-3}$ Since removal of dying cells and cell debris is essential for the survival of multicellular organisms, this task can be taken over by an armada of different cells, ranging from hepatocytes, mesangial cells and fibroblasts to professional macrophages derived from blood monocytes or residing in the brain, that is, microglia.

Programmed cell death (PCD) can take multiple forms and pathways. ${ }^{3}$ Apoptosis, for instance, involves activation of the evolutionarily widely conserved proteases of the caspase family. Apoptosis is the biochemically and morphologically best-defined form of programmed cell death (PCD), ${ }^{4,5}$ and the mechanisms of phagocytic recognition are best studied for apoptotic cells. Membrane alterations cause the presentation of recognition molecules, which are normally masked or restricted to the inner membrane ${ }^{6}$ The usually asymmetrically distributed phospholipid phosphatidylserine (PS), for example, is randomized across the lipid bilayer during apoptosis and thus exposed on the cell surface. This may be due to either a loss of the ATP-dependent aminophospholipid translocase activity and/or enhanced transbilayer movement of phospholipids, sometimes enhanced by a $\mathrm{Ca}^{2+}$-dependent phospholipid scramblase or possibly the action of $\mathrm{ABC} 1 /$ Ced7. ${ }^{7,8}$ Subsequently, PS may serve as a trigger for recognition by various receptors on macrophages such as the PS receptor (PSR) or $\mathrm{CD} 14^{9}$ to initiate the ingestion of the cell corpses. ${ }^{10}$ In contrast to the phagocytosis of microbes, the uptake of apoptotic cells commits macrophages to release anti-inflammatory factors, such as TGF $\beta,{ }^{11,12}$ and to inhibit the secretion of proinflammatory mediators such as TNF $\alpha .{ }^{11,12}$ A similar PS translocation as in apoptosis has been demonstrated in many instances of apoptosis-like PCD, although caspases are not required here (reviewed in Leist and Jaattelra $\left.{ }^{3}\right) .^{13-15}$

Much less information is available for cell death with necrotic morphology. Uncontrolled necrosis is a passive death process. It typically occurs following exposure to high concentrations of endogenous or exogenous toxins, heat treatment, freeze thawing or other immediately disruptive insults. ${ }^{3,16}$ Leakage of noxious contents from necrotic cells can cause injury to the surrounding tissue and initiates the activation or potentiation of proinflammatory responses. Morphologically similar to, but mechanistically different from, necrosis is necrotic PCD. ${ }^{3}$ As apoptosis, necrotic PCD relies on defined intracellular mechanisms such as AIF activation, ${ }^{17}$ cathepsin activation, ${ }^{15}$ RIP activation on death receptors ${ }^{18}$ or control by Bcl-2. ${ }^{1,20}$ Sometimes, apoptosis, for example, by staurosporine (STS) treatment or CD95 (Fas, Apo-1)-ligation, can be converted into necrotic PCD when cells are devoid of energy production ${ }^{20-22}$ or when caspases are inhibited. ${ }^{23} \mathrm{We}$ have also shown that various types of necrotic/nonapoptotic cells may be removed relatively quickly following membrane lysis. ${ }^{13,24}$ However, little is known about phagocytic recognition of necrotic cells, for instance, because conventional annexin V staining methods cannot discriminate between PS on the outer and inner leaflet of lysed cells. In the present study, we developed a method to show that necrotic PCD can involve the exposure of PS on the surface, which may then serve as a major recognition signal for their rapid removal by macrophages. Furthermore, we show that phagocytosis of 
necrotic PCD corpses occurs rapidly, and as efficient as with apoptosis targets. Necrotic PCD, unlike necrosis, blunted the secretion of proinflammatory mediators, and thus might provoke only limited inflammation and damage to the surrounding tissue. All essential data obtained in a human macrophage-based model were consistently reproduced throughout with murine microglia-like cells.

\section{Results}

\section{Effect of different types of cell corpses on macrophage TNF $\alpha$ secretion}

Some nonapoptotic cells can be phagocytosed similar to apoptotic cells. ${ }^{13,24}$ The uptake of apoptotic cells can actively suppress the secretion of proinflammatory mediators such as TNF $\alpha$ by activated macrophages. ${ }^{11,25}$ Here we examined whether TNF suppression might also be affected by nonapoptotic cells. We used the previously characterized experimental systems of human monocyte-derived macrophages (HMDM) or murine microglia-like BV-2 cells exposed to Jurkat cells undergoing different types of cell death. Incubation of macrophages with Escherichia. coli particles resulted in a massive production of TNF $\alpha$. Jurkat cells were challenged with STS to undergo apoptosis under normal metabolic conditions. Such apoptotic cells retained their plasma membrane integrity for $4-5 \mathrm{~h},{ }^{13}$ that is, throughout the entire period of the experiments. As expected, TNF production was attenuated by apoptotic cell, and left unaffected by heat-killed necrotic cells (nec II) or by healthy cells. Target cells with necrotic morphology, but PCD history (nec I; ATP-depleted plus STS), suppressed TNF as effectively as apoptotic cells (Figure $1 \mathrm{a}+\mathrm{b})$. We also examined whether the effect on macrophages was affected by the age, and possibly secondary changes, of the cell corpses. For this purpose, the different cell populations were incubated with HMDM for $18 \mathrm{~h}$, before they were washed and the inflammatory stimulus was added. Modulation of the TNF response was not different from the $2 \mathrm{~h}$ incubation experiment. Furthermore, we closely examined the basic proinflammatory effects of the different corpses on BV-2 cells. Apoptotic and nec I cells had no effect at all on basic TNF release, while nec II cells showed a consistent, but very low (TNF $<100 \mathrm{pg} / \mathrm{ml}$ ) proinflammatory effect. Basal TNF release on HMDM was in all instances under the lower detection limit. Taken together, these data imply that not all necrotic cells behave in the same way, and some may exert anti-inflammatory effects on macrophages. This may not necessarily be only due to the specific surface changes, but necrotic cells may further modulate the antiinflammatory effect of PS by the release of HSP $70,{ }^{26}$ proteases, ${ }^{27}$ or lipid mediators acting on PPAR-gamma or the liver $X$ receptor. ${ }^{28}$ The interaction of nec I cells (in the following for simplicity just called necrotic) with macrophages was followed further.

\section{Competition between apoptotic and necrotic cells for phagocytosis}

Necrotic cells might be recognized via the same recognition molecules as apoptotic cells ${ }^{29}$ and compete with apoptotic

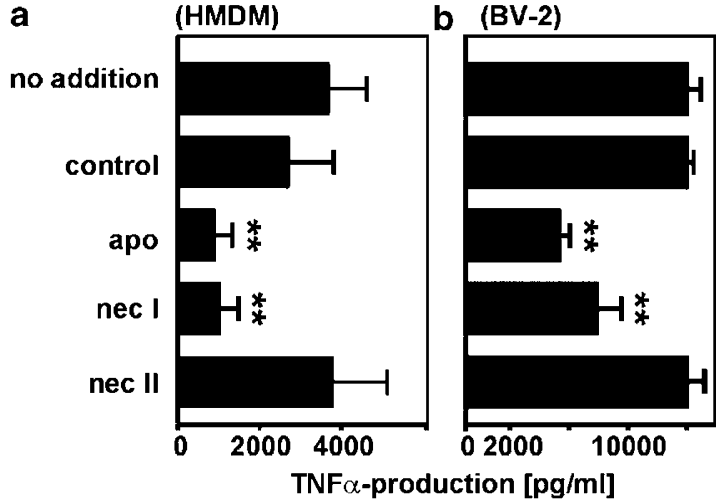

Figure 1 TNF $\alpha$ response of macrophages to cells. Jurkat cells were challenged with STS $(1 \mu \mathrm{M})$ for $2 \mathrm{~h}$ in the presence (apo) or for $5 \mathrm{~h}$ in the absence of ATP (nec I), respectively, or subjected to hyperthermia $\left(56^{\circ} \mathrm{C}, 30 \mathrm{~min}\right.$, nec II) or left untreated. These targets were added to HMDM (a) or BV-2 (b) at a ratio of target cells: macrophages of $5: 1$ and incubated for $2 \mathrm{~h}$. Following removal of Jurkat cells, macrophages were treated with $E$. coli particles $(5 \mu \mathrm{g} / \mathrm{ml})$. Supernatants were collected $17 \mathrm{~h}$ later and TNF $\alpha$ were concentrations determined by ELISA. Cells without $E$. coli did not show a significant TNF response. Data are means \pm S.D. from triplicate determinations. ${ }^{* \star} P<0.01$.

cells for uptake by macrophages in pathological situations where they co-occur. ${ }^{16}$ To analyze this, we expanded our previously developed phagocytosis assay ${ }^{13}$ by additionally labeling the target cells with the cell impermeant DNA-dye SYTOX shortly before co-culturing with HMDM. This third fluorescent parameter allows the distinction between phagocytosed cells that had intact membranes at the time point of uptake from those whose membranes were perforated; or in other words between cells that were apoptotic or necrotic in a mixed experimental system. Apoptotic cells were mixed with necrotic cells in various ratios and presented to HMDM for phagocytosis. The amount of necrotic, ingested cells was determined by quantitating green (SYTOX-positive, necrotic) ingested cells. Surprisingly, the prevailing ingested type of cell was SYTOX-positive already at low amounts of necrotic cells in the mixture (Figure 2a), arguing for a predilection of HMDM for necrotic cells with lysed membranes.

In a further set of experiments, we included a constant number of Fast Blue-labeled apoptotic Jurkat cells in the phagocytosis assay and added varying quantities of unlabeled necrotic cells. Interestingly, the uptake of apoptotic cells markedly decreased in the presence of even small amounts of necrotic cells, further indicating a preference of macrophages for necrotic cells (Figure 2b).

To demonstrate in more detail that the double-labeled cells were indeed ingested by macrophages, we examined the phagocytosis qualitatively by confocal microscopy. Both apo and nec cells could be detected by their blue fluorescence inside HMDM on a single cell basis (Figure 3). In addition, necrotic cells could be spotted by the green fluorescence, originating from their SYTOX-stained DNA (Figure 3). This expansion of the assay clearly permits the distinction of necrotic from apoptotic cells within phagocytes by confocal scanning. 


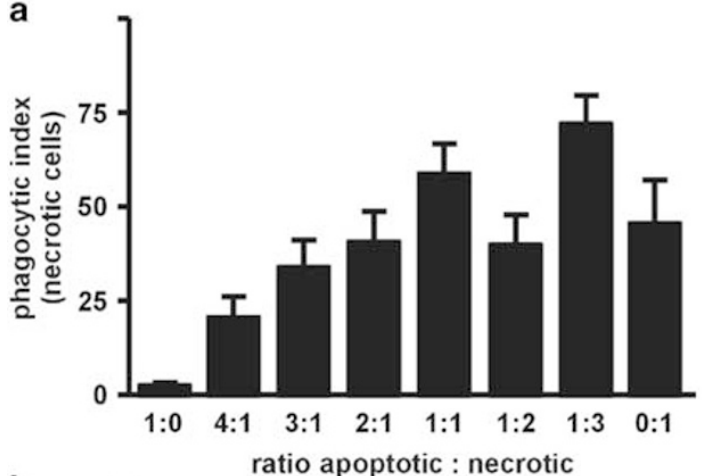

b

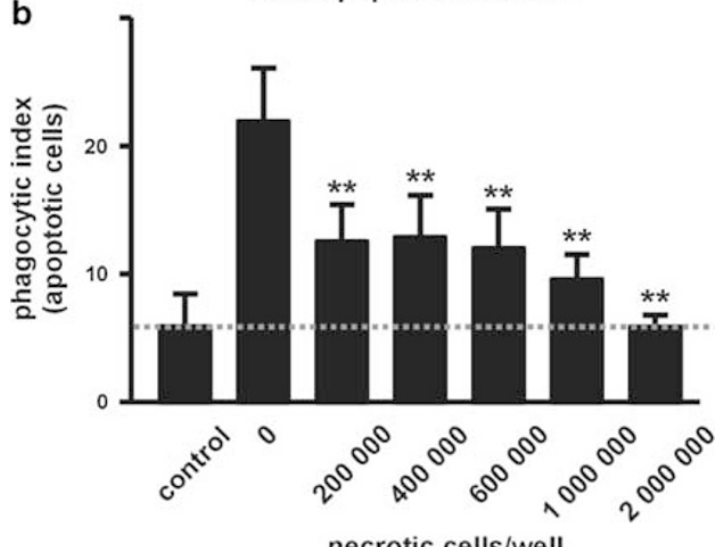

Figure 2 Competition between apoptotic and necrotic cells for phagocytosis. (a) A fixed amount of Jurkat cells consisting of different ratios of apo $(1 \mu \mathrm{M}$ STS, $2 \mathrm{~h}$ ) and nec (1 $\mu \mathrm{M}$ STS, $5 \mathrm{~h}$, no ATP; stained with SYTOX and washed shortly before addition to HMDM) cells were incubated with HMDM for $1 \mathrm{~h}$. Ingested nec cells were scored as SYTOX-positive particles inside HMDM. (b) A fixed number $\left(1 \times 10^{6} /\right.$ well) of Fast Blue-labeled apo cells were added together with increasing amounts of nec Jurkat to HMDM. Following $1 \mathrm{~h}$ of interaction, ingested apo cells were scored by their blue fluorescence. Values are means \pm S.E.M. of five independent experiments.

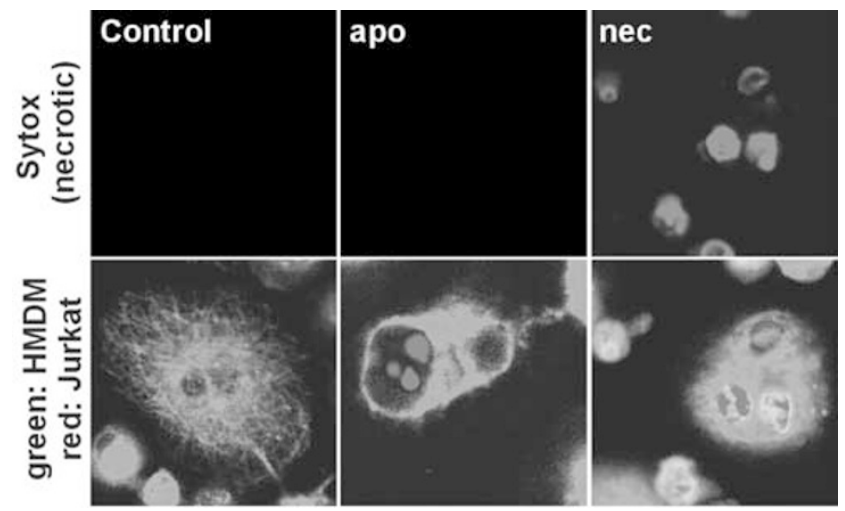

Figure 3 Experimental model for the detection of phagocytosis of necrotic Jurkat cells. HMDM (stained with Dil, green) and Jurkat cells (stained with Fast Blue, red) were treated with STS at normal (apo) or low (nec) glucose concentrations or left untreated. Following treatment, Jurkat cells were additionally stained with SYTOX (upper panel, purple). After $1 \mathrm{~h}$ of interaction with HMDM, representative confocal micrographs were recorded.

\section{Role of PS in recognition of necrotic cells by macrophages}

We investigated the factors that are involved in the efficient recognition and phagocytosis of cells dying by necrotic PCD. Since PS exposure is the most striking and abundant surface change on apoptotic cells and many forms of apoptosis-like $\mathrm{PCD},{ }^{3}$ we also examined whether necrotic cells with lysed plasma membranes are recognized via PS by macrophages. To test this, HMDM were incubated with pure phosphatidylcholine (PC)-liposomes or PC-liposomes enriched with PS, 30 min prior to co-culture with Jurkat target cells. Jurkat cells were induced to undergo necrosis by ATP depletion and exposure to STS or treated with ionomycin to induce PS exposure with otherwise normal appearance as a positive control. ${ }^{13}$ The phagocytosis of both kinds of Jurkat cells was almost completely prevented by competitive action of PS- but not PC-liposomes (Figure 4a). To further test this PS dependency, phagocytic meals were incubated with recombinant annexin $V$ prior to their co-incubation with HMDM to mask PS molecules on their surface. Ionomycin-treated and necrotic cells pretreated in such a way were almost completely refused by HMDM, which further points to a PSdependent uptake (Figure 4a).

Identical experiments were performed with the murine microglia cell line BV-2 instead of HMDM. Here, apoptotic cells were used as a positive control, since BV-2 cells are not capable of ingesting ionomycin-treated Jurkat cells. Inhibition of the PS-recognition pathway almost completely blocked the uptake of necrotic cells (Figure 4b). However, the phagocytosis of apoptotic cells by BV-2 seems to depend only to a minor extent on the recognition of PS, as described previously for other cells. ${ }^{30-32}$

There might, however, still be the possibility that also PSindependent recognition pathways are involved in the recognition and ingestion of necrotic cells by HMDM. Therefore, we tested additional well-characterized recognition systems. Although pretreatment of macrophages with RGDS or antibodies against CD36 or CD14 could partially inhibit the uptake of apoptotic cells, all inhibitors were ineffective in inhibiting the uptake of cells dying by necrosis in this system (Figure 4c). We also used antibody mAB217 against the PSR for blocking experiments with HMDM. Up to $100 \mu \mathrm{g} / \mathrm{ml}$ had no significant inhibitory effect, compared to, for example, $10 \mu \mathrm{g} /$ $\mathrm{ml}$ anti-CD14. Upon blockage of PSR on BV-2 cells, we observed a $20 \pm 7 \%$ reduction of phagocytosis at $100 \mu \mathrm{g} / \mathrm{ml}$, but no significant effect at $10 \mu \mathrm{g} / \mathrm{ml}$.

\section{Real-time observation of PS-dependent uptake of necrotic corpses}

Consistently, throughout this study necrotic cells appeared to be taken up more efficiently than apoptotic or ionomycintreated cells. To gain proof about this unexpected observation, we followed the fate of necrotic Jurkat cells directly by time lapse microscopy. Jurkat cells induced to undergo necrotic PCD were quickly taken up by BV-2 (Figure $5 a, b$, video $1+2)$. However, when treated Jurkat cells were preincubated with recombinant annexin $\mathrm{V}$ to mask their surface PS, they were for the most part rejected by 

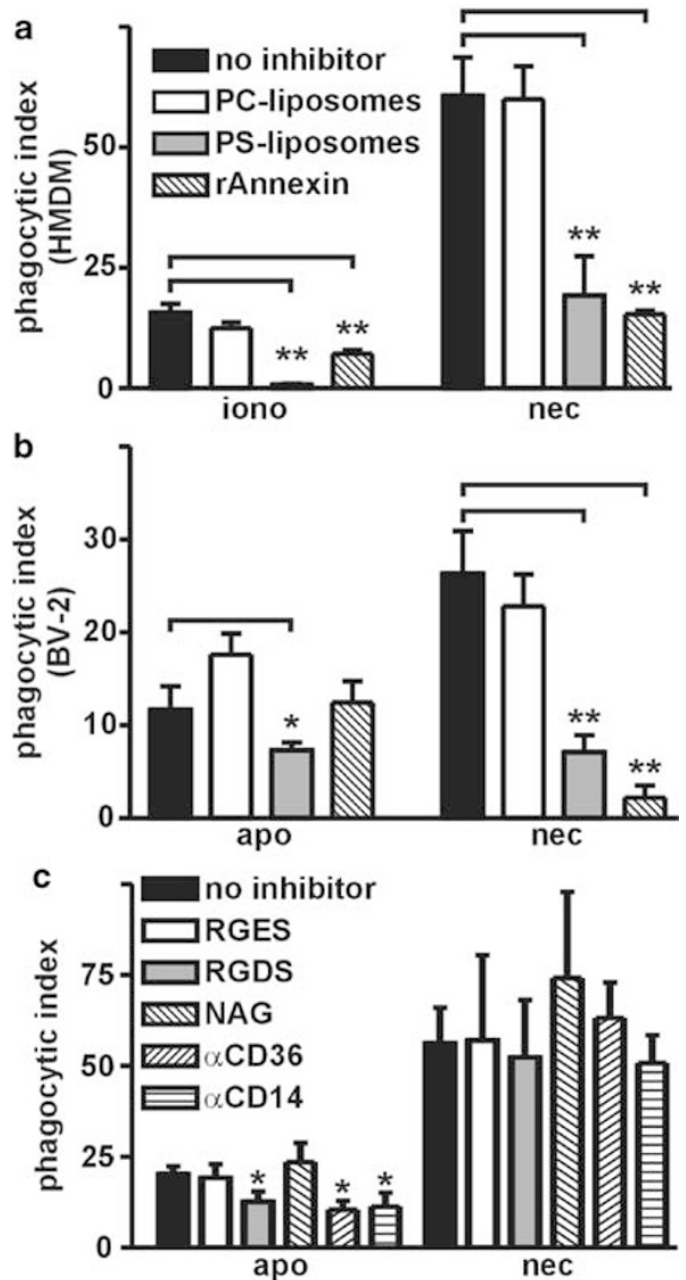

Figure 4 PS-dependent recognition of necrotic cells. Jurkat cells were added to HMDM (a) or BV-2 (b) in the presence or absence of PC- or PS-liposomes or recombinant annexin V $(120 \mu \mathrm{g} / \mathrm{ml})$, and the phagocytic indices were scored microscopically. (c) Jurkat cells (apo or nec) were added to HMDM in the presence of Arg-Gly-Asp-Ser (RGDS, 2 mM), Arg-Gly-Glu-Ser (RGES 2 mM) Nacetyl glucosamine (NAG, $40 \mathrm{mM})$, antibodies against CD36 $(\alpha \mathrm{CD} 36,10 \mu \mathrm{g} / \mathrm{ml})$ or CD14 $(\alpha \mathrm{CD} 14,40 \mu \mathrm{g} / \mathrm{ml})$ or with medium alone. Subsequently, phagocytic indices were scored microscopically. Data are means \pm s.e.m. of $3-5$ experiments from different preparations. ${ }^{*} P<0.05 ;{ }^{* *} P<0.01$.

macrophages and persisted untouched between them for several hours (Figure $5 c$, video 3). Taken together, these data imply that Jurkat cells induced to undergo necrotic PCD are quickly removed by macrophages by a mainly PS-dependent recognition mechanism.

\section{PS exposure on the outer surface of lysed necrotic cells}

The question remains open as to whether necrotic cells in fact display PS on their outer surface. Therefore, we developed an assay that specifically detects PS on the outer membrane of cells. Following labeling with annexin $\mathrm{V}$ coupled to biotin, cells were incubated with streptavidin-coated magnetic beads. These beads have a size of $2.8 \mu \mathrm{m}$ in diameter, thus being excluded from cells, even when their plasma membranes are perforated (Figure $6 \mathrm{~b}$ and controls in methods). Separation of

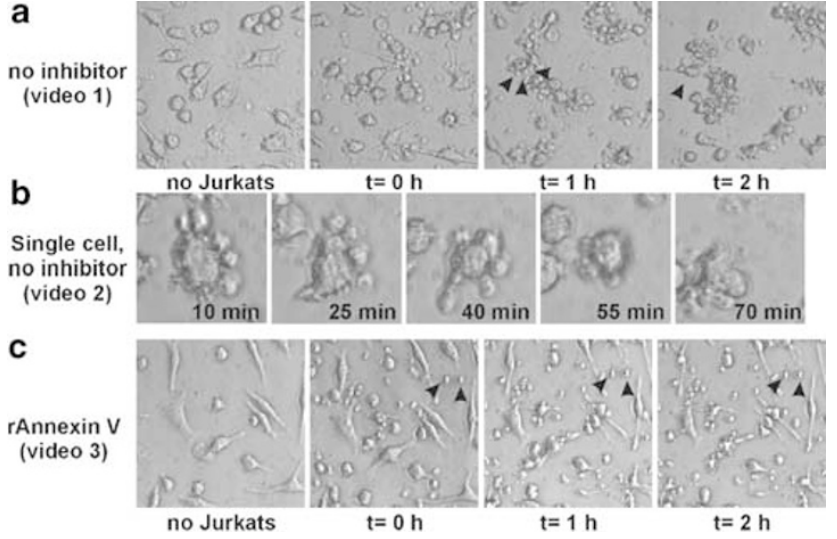

Figure 5 Time-lapse recording of BV-2 macrophages phagocytosing necrotic Jurkat cells. Jurkat cells induced to undergo necrotic PCD were co-cultured with BV-2 cells and recorded by time-lapse video microscopy (also see supplementary videos available at http://www.???). (a/video 1) Arrowheads indicate Jurkat cells that are removed by macrophages over a time period of $2 \mathrm{~h}$. Note that macrophages interact with Jurkat cells almost immediately after their addition. (b/video 2) A single macrophage from video 1 is clipped out that ingests three target cells. (c/video 3 ) Conditions as in (a), but preincubation of Jurkat with recombinant annexin V $(120 \mu \mathrm{g} / \mathrm{ml})$ for $10 \mathrm{~min}$, presented to BV-2 and recorded by time-lapse microscopy. Note that macrophages mostly ignore these necrotic Jurkat cells, which persist for more than $2 \mathrm{~h}$ (arrowheads show two examples).

PS-surface-positive from -negative cells was achieved in a horizontal magnetic field, herein referred to as PS-surface MACS (MACS; magnetic cell sorting). Examination of ionomycin-treated and necrotic Jurkat cells for PS-surface exposure by this method revealed that both kinds of cells were highly positive (Figure 6a). When the assay was carried out in a $\mathrm{Ca}^{2+}$-free buffer or in the presence of recombinant annexin $\mathrm{V}$ as competitive inhibitor for annexin V-biotin, the separation was abolished, demonstrating that this assay is specific for PS labeling by annexin $\mathrm{V}$ (Figure 6a).

As a further control, the surface expression of apoptotic and prenecrotic cells was compared. Jurkat cells treated with STS (apo) were highly positive, whereas ATP-depleted prenecrotic (intact plasma membrane) and control cells were not (Figure 6c). This confirmed earlier data obtained by conventional annexin V-FITC staining. ${ }^{13}$ These experiments indicate that necrotic cells may also expose PS on their surface, but only after membrane lysis, and that this serves as a major recognition molecule for their phagocytosis by macrophages. We also incubated heat-treated (nec II) cells with PSliposomes or PC-liposomes and observed a selective block of uptake by PS. Thus, also unscheduled necrotic cells can be taken up in a PS-dependent manner.

\section{Modulation of PS exposure on lysed necrotic cells}

Upon necrosis, large amounts of extracellular $\mathrm{Ca}^{2+}$ enter cells, and scrambling of phospholipids can be promoted by already small increases in $\left[\mathrm{Ca}^{2}+\right]_{\mathrm{i}} \cdot{ }^{33}$ In order to investigate if $\mathrm{Ca}^{2+}$ is required for PS exposure on lysed cells, a variety of treatments were applied that induce necrotic cell lysis under $\mathrm{Ca}^{2+}$-free conditions. A problem with this approach is that both phagocytosis and PS-surface MACS require the presence of $\mathrm{Ca}^{2+}$. Therefore, cells were fixed very rapidly in 

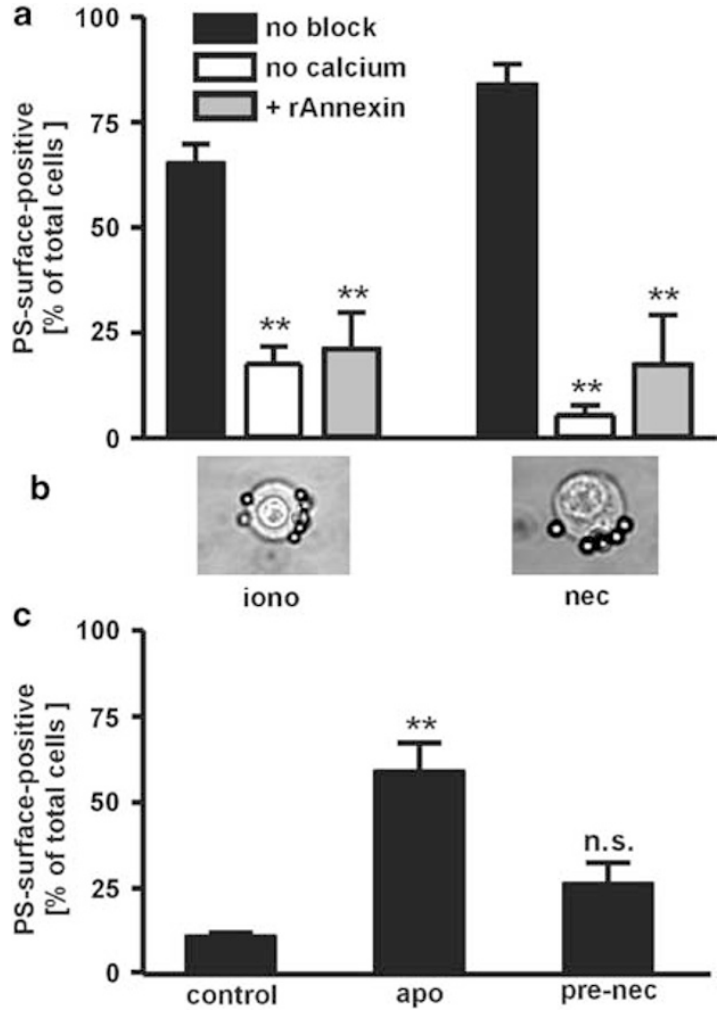

Figure 6 Detection of PS on the surface of necrotic cells. (a) Following challenge, Jurkat cells were labeled with annexin V-biotin in the presence (black bars) or absence of $\mathrm{Ca}^{2+}$ (white bars), or in the presence or absence of recombinant annexin V $(100 \mu \mathrm{g} / \mathrm{ml}$, gray bars $)$, washed and mixed with streptavidin-coated particles. Separation of PS-surface-positive cells was achieved by incubating the suspension in a horizontal magnetic field. PSsurface-positive cells were evaluated by counting magnetic and nonmagnetic cells using a hemocytometer. (b) Representative phase contrast micrographs of magnetic streptavidin-coated particles attached to treated Jurkat cells. (c) Jurkat cells were treated with STS $(1 \mu \mathrm{M})$ in the presence (apoptotic) or absence (prenecrotic) of ATP for $2 \mathrm{~h}$. The number of PS-surface-positive cells was evaluated by PS-surface MACS. Data are means \pm S.E.M. of four experiments from different preparations. ${ }^{\star} P<0.05 ;{ }^{* *} P<0.01 ;$ n.s.: not significant.

paraformaldehyde (PFA) after exposure to death-triggering conditions. Surface PS was then analyzed on these fixed cells. In initial studies we tested whether cells challenged to expose PS on their surface by stimuli previously described preserve this asymmetry after fixation and are equally phagocytosed compared to nonfixed cells. PFA fixation of control, ionomycin-treated apoptotic or necrotic cells did not influence the state, detection of PS-surface exposure or phagocytosis by HMDM (Figure 7a). It is important to note that PFA fixation is known to keep the lipid in place by lightly fixing the membrane, but not affecting the lipids themselves. Cells treated first with formaldehyde and then digitonin resemble typical necrotic cells on FACS (SYTOX permeable, calcein permeable, little changed scatter, good chromatin detection, no loss of mitochondrial mass, loss of mitochondrial and membrane potential). These cells were MACS -negative, that is, PS stayed inside and could not be stained despite membrane permeabilization (Figure 7b). PS could be scrambled out by repeated freeze-thaw. Such cells still retained their overall structure as confirmed by microscopy

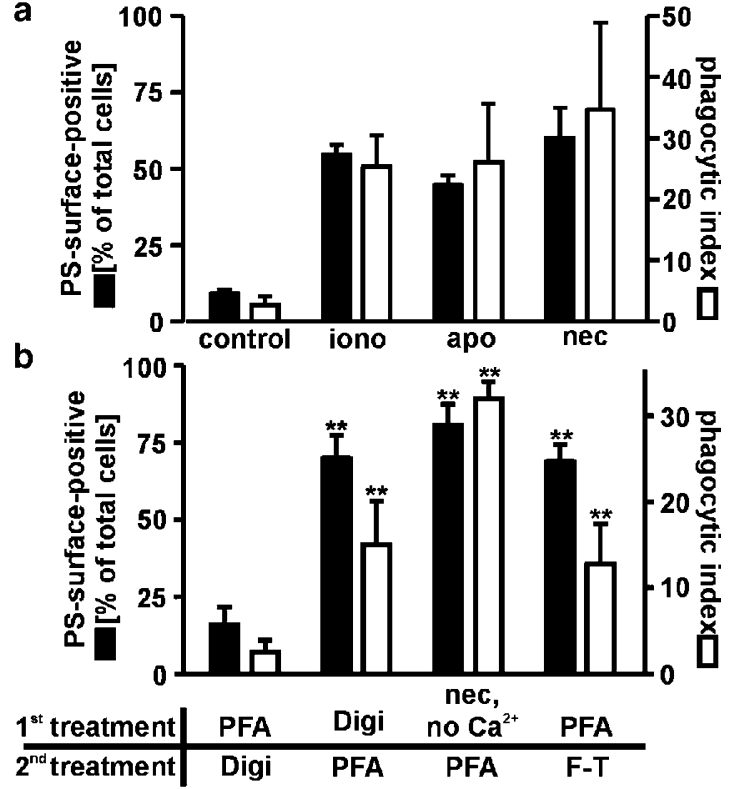

Figure 7 Modulation of PS exposure on necrotic cells. (a) Following challenge as indicated, Jurkat cells were rapidly fixed in $2 \%$ PFA. PS-surface exposure (black bars) and phagocytosis by HMDM (white bars) were subsequently determined. (b) Jurkat cells were rapidly fixed in $2 \%$ PFA before or after lysis in digitonin $\left(100 \mu \mathrm{g} / \mathrm{ml}\right.$, Digi), before three cycles of freezing and thawing $\left(-80^{\circ} \mathrm{C}\right.$, F-T) or cells were fixed in PFA following treatment with STS $(1 \mu \mathrm{M})$ in the absence of $\mathrm{Ca}^{2+}$ (incubation in PBS plus $0.2 \mathrm{mM} \mathrm{EGTA}$ ) and ATP for $18 \mathrm{~h}$ (nec, no $\mathrm{Ca}^{2+}$ ). Following these treatments, PS-surface exposure by MACS (black bars) or phagocytosis by HMDM (white bars) was evaluated. Data are means \pm S.E.M. of four experiments from different preparations. ${ }^{*} P<0.05$; ${ }^{* \star} P<0.01$.

and then became MACS-positive. Cells treated by the reverse protocol, first digitonin, then formaldehyde, looked morphologically absolutely similar, but were MACS-positive (Figure $7 \mathrm{~b}$ ).

To test whether PS exposure on lysed cells is a simple consequence of raised calcium or whether it can occur independently, Jurkat cells were subjected to a short and mild treatment with the detergent digitonin in $\mathrm{Ca}^{2+}$-free conditions. ${ }^{34}$ This treatment resulted in whole cells with perforated, but otherwise maintained, plasma membranes ( $>90 \%$ SYTOX-positive). Such digitonin-treated 'necrotic' Jurkat cells were examined for PS-surface exposure and phagocytosis. Analysis of such cells by PS-surface MACS revealed that PS was present on their surface (Figure $7 \mathrm{~b}$ ). Furthermore, digitonin-treated cells were readily taken up by HMDM. To exclude that this PS exposure is due to PFA fixation rather than to digitonin treatment, Jurkat cells were fixed in PFA before exposure to digitonin. These cells were negative for surface PS and failed to be ingested by HMDM (Figure 7b), indicating that PS exposure can be provoked rapidly, but independent of calcium by digitonin in Jurkat cells.

As a second approach to elucidating the role of $\mathrm{Ca}^{2+}$ in necrotic PS exposure, necrotic PCD was induced under $\mathrm{Ca}^{2+}$-free conditions. Cell lysis occurred at a considerably later time point compared to conditions when $\mathrm{Ca}^{2+}$ is present, that is, after $18 \mathrm{~h}$ most of the cells ( $\geqslant 90 \%)$ were SYTOXpositive. Such Jurkat cells were rapidly fixed in PFA to prevent a secondary $\mathrm{Ca}^{2+}$-induced PS exposure during assays. Also 
in this model system, cells were highly positive for surface PS, which correlated well with phagocytic uptake by HMDM (Figure 7b). Taken together, these data imply that PS exposure and subsequent phagocytosis occur rapidly as a consequence of cell membrane permeabilization, but do not require $\mathrm{Ca}^{2+}$ influx. Thus, in some forms of necrosis, plasma membrane lysis by itself might be sufficient to initiate randomization of PS, while in other forms of necrosis, the associated degradative processes might be counteracting/ preventing this.

\section{Discussion}

In many pathological situations, apoptosis and necrosis occur simultaneously. The signals emanating from necrotic cells are of great interest, since different ways of recognition and uptake of dying cells have a major implication on immunological parameters. For instance, we showed here that the exact mode of necrotic death has an essential impact on the kind of immunological response of phagocytes. In fact, uptake of 'programmed necrotic' (ATP-depleted; lysed) Jurkat cells clearly inhibited the E. coli-induced TNF $\alpha$ secretion by HMDM to a comparable extent as the uptake of apoptotic cells. Heat-killed (unscheduled necrotic) cells, however, failed to inhibit the proinflammatory reaction by macrophages. This agrees well with earlier reports that such unspecific necrotic cells contribute to a proinflammatory milieu in many systems. ${ }^{35,36}$ It also fits with the report that the phagocytic machinery for the elimination of apoptotic cells is also utilized for the removal of some programmed necrotic corpses in C. elegans, ${ }^{29}$ and that some necrotic cells are not proinflammatory. ${ }^{37}$ Taken together, these data suggest that different forms of necrotic cell death alter inflammatory reactions by macrophages, and that a finer characterization of nonapoptotic death types will be important in the future.

But what determines the kind of response a dead cell triggers? It seems obvious that PS on necrotic cells could interact with the PSR when encountering phagocytic cells. Binding to the PSR is considered to provoke an antiinflammatory milieu ${ }^{10}$ and this might consequently explain why certain lysed cells suppress proinflammatory responses by macrophages in this and other studies. ${ }^{36}$ The removal of necrotic cell types might be less efficient, for instance, under conditions of massive tissue damage, associated with macrophage impairment and oxidative stress. ${ }^{38}$ Corpses may then persist longer, and leak considerably more contents into the extracellular space than necrotic cells that are rapidly removed. More intriguingly, the intracellular contents of individual cell types might determine the kind of immune response they trigger, following lysis. Necrotic neutrophils, for instance, release proteases such as elastase, which degrades surface structures on macrophages including the PSR, thus abolishing anti-inflammatory reactions. ${ }^{36}$ Other cell types such as lymphocytes (Jurkat cells), however, might contain rather small quantities of such preformed intracellular proteases and consequently fail to cause similar reactions. ${ }^{36,39}$ In addition, under conditions of heat stress, for instance, newly synthesized components of the stress response pathway, such as HSP70, might leak out of the cells following lysis, ${ }^{40}$ and may then contribute to proinflammatory conditions. ${ }^{26}$ Especially, different lipid metabolites have pronounced pro- or anti-inflammatory effects, which might play a role upon phagocytosis of necrotic material (LXR-ref)

One key finding of our study is that in a head-to-head comparison within the same assay system, necrotic cells seemed to be preferred by HMDM over apoptotic cells and were removed more efficiently or more rapidly. This extends our previous observations giving first evidence of efficient removal of nonapoptotic corpses. ${ }^{13}$ In further support of our finding, we also used another system of nonapoptotic death, LoVo36 cells incubated with HSP70 antisense, ${ }^{24}$ where we left cells until they lysed. Also here the uptake was blocked by $85 \%$ by PS-liposomes, but not by PC-liposomes (data not shown). Although we cannot provide a molecular explanation for the observation of rapid necrotic cell removal, studies by others indicate that PS on necrotic cells might be highly oxidized, which accelerates their recognition. ${ }^{41}$

A recent report suggested that the uptake of necrotic cells is not specified exclusively by PS exposure. ${ }^{42}$ In that study, however, a rather artificial model of necrosis induced by hyperthermia was utilized. In contrast, the uptake of cells dying by a pathological relevant form of necrosis in our study appeared to depend predominantly on PS recognition. Inhibitors of this recognition pathway almost completely blocked necrotic cell uptake, and the dependence on PS recognition appeared to be more pronounced than even for classical apoptotic cells. One might speculate that loss of activity of the ATP-dependent aminophospholipid translocase, which moves PS from the outer to the inner leaflet in healthy cells, ${ }^{43,44}$ might account for a passive PS randomization in the membranes of necrotic cells. In fact, necrosis is frequently associated with impaired intracellular ATP levels. ${ }^{21,22,45}$ Energy-deprived cells might contain just sufficient ATP (i.e. a residual ATP concentration $<0.8 \mathrm{nmol} / \mathrm{mg}$ protein ${ }^{21}$ ) to preserve the PS-membrane asymmetry. Shortly before lysis, ATP levels collapse completely and, consequently, PS is randomized between the inner and outer leaflet due to inactivity of the translocase.

One important question concerns timing of events. Cells can sometimes be rescued even after the death programe has been triggered. ${ }^{1,46}$ The 'point of no return' defines the step in the signaling/execution cascade, beyond which cells are irrevocably doomed. Phagocytosis itself might represent the decisive point of no return. For 'undecided' cells, it is thus essential to halt the display of phagocytosis markers until their demise is inevitable. For instance, ATP-depleted cells might remain for extended times in a slowed or haltered state of the death programe and might display PS just in the last moment when their deletion is unavoidable, that is, shortly before or at lysis. Notably, the rapid kinetics of PS exposure (minutes ${ }^{47,48}$ ) might be particularly useful for necrotic cell death, where a point of no return is not reached until the membrane breaks, and then requires a fast display of phagocytosis markers that are essential for the rapid removal of corpses. 


\section{Materials and Methods}

\section{Chemicals and antibodies}

Octadecyl $\left(\mathrm{C}_{18}\right)$, indocarbocyanine (Dil) and Sytox were obtained from Molecular Probes (Eugene, OR); FITC- and biotin-conjugated annexin V were from Roche (Mannheim, Germany); recombinant annexin $V$ and purified mouse anti-human CD36 monoclonal antibody were from Pharmingen (Heidelberg, Germany); and purified mouse anti-human CD14 monoclonal antibody clone RMO52 was from Coulter-Immunotech (Krefeld, Germany). mAB217 was a kind gift of Valerie Fadok from the National Jewish Medical and Research Center, Denver, Colorado. All other reagents were from Sigma (Deisenhofen, Germany), Merck (Darmstadt, Germany) or Riedel-de Haen (Selze, Germany).

\section{Preparation of monocyte-derived macrophages}

Human monocytes were isolated as described previously. ${ }^{13}$ In brief, $250 \mathrm{ml}$ of peripheral venous blood was drawn from a single volunteer. Citrate $(0.31 \% \mathrm{w} / \mathrm{v})$ was used as an anticoagulant. The blood was diluted 1.6-fold with phosphate-buffered saline (PBS; $2 \mathrm{mM} \mathrm{NaH}_{2} \mathrm{PO}_{4}, 16 \mathrm{mM}$ $\left.\mathrm{Na}_{2} \mathrm{HPO}_{4}, 150 \mathrm{mM} \mathrm{NaCl}(\mathrm{pH} 7.4)\right)$ prior to centrifugation at $220 \times g$ at $20^{\circ} \mathrm{C}$ for $20 \mathrm{~min}$. The cell pellet was layered on a Percoll gradient $(\rho=1.077 \mathrm{~g} / \mathrm{ml})$ and the interphase containing the peripheral blood mononuclear cells (PBMC) was obtained following centrifugation at $800 \times g$ for $10 \mathrm{~min}$. Cells were washed twice in elutriation medium (PBS, $2 \%$ heat-inactivated human $A B$ serum, $2 \mathrm{mM}$ EDTA, $5 \mathrm{mM}$ glucose $(\mathrm{pH}$ 7.4)) prior to countercurrent centrifugal elutriation of the cells using a J2$\mathrm{MC}$ centrifuge equipped with a JE-6B rotor. The monocyte-containing fraction was obtained at a flow rate of $39 \mathrm{ml} / \mathrm{min}$ and a rotor speed of $3000 \mathrm{rpm}$. Elutriated monocytes were plated at an initial density of $2 \times 10^{5}$ cells/well on 48-well culture dishes. After $60 \mathrm{~min}$ at $37^{\circ} \mathrm{C}$, nonadherent cells were removed and the medium was exchanged for fresh RPMI 1640 containing 10\% heat-inactivated human AB serum and antibiotics (penicillin, $5000 \mathrm{IU} / \mathrm{ml}$; streptomycin, $5 \mathrm{mg} / \mathrm{ml}$ ). Monocytes were differentiated to macrophages for 8-12 days in a volume of $0.5 \mathrm{ml} /$ well on 48-well culture dishes. Medium was exchanged 5 days after plating and before experiments. HMDM were used for experiments between days 7 and 12 after plating.

\section{Cell culture and treatments of Jurkat cells}

Jurkat cells (human T-cell lymphoma, clone E6, ATTC No. TIB-152) and BV-2 cells (murine microglia cells, kind gift of Dr. Blasi, University Medical School Perugia, Italy ${ }^{49}$ ) were propagated in RPMI 1640 medium supplemented with $10 \%$ heat-inactivated FCS, antibiotics (penicillin, $10000 \mathrm{U} / \mathrm{ml}$; streptomycin, $10 \mathrm{mg} / \mathrm{ml}$ ) and glutamine $(2 \mathrm{mM})$. All experiments were performed in RPMl 1640 without serum. Apoptosis (apo) was triggered by addition of staurosporine (STS, $1 \mu \mathrm{M}, 2 \mathrm{~h}$ ). Treatment with ionomycin was performed by incubating Jurkat cells in annexin $\mathrm{V}$-binding buffer (100 mM HEPES/NaOH (pH 7.4), $140 \mathrm{mM} \mathrm{NaCl}, 2.5 \mathrm{mM} \mathrm{CaCl}_{2}$ ) containing ionomycin $(2 \mu \mathrm{M})$ to achieve high $\left[\mathrm{Ca}^{2+}\right]_{i}$-conditions. STStriggered necrosis (necrotic PCD, nec) was induced by treating Jurkat cells with STS under conditions of ATP depletion, which was achieved by incubating Jurkat cells in serum- and glucose-free medium for $30 \mathrm{~min}$, following incubation for an additional $30 \mathrm{~min}$ in serum- and glucose-free medium in the presence of $2.5 \mu \mathrm{M}$ oligomycin. ${ }^{21}$ Rapid and mild lysis of Jurkat cells was performed as described recently. ${ }^{34}$ Briefly, confluent Jurkat cells were centrifuged and resuspended in MSH buffer $(210 \mathrm{mM} \mathrm{D}$ mannitol, $70 \mathrm{mM}$ sucrose, $10 \mathrm{mM}$ HEPES, $0.2 \mathrm{mM}$ EGTA, $5 \mathrm{mM}$ succinate, $0.15 \% \mathrm{BSA}$ ) containing $100 \mu \mathrm{g} / \mathrm{ml}$ digitonin and incubated for $5 \mathrm{~min}$ on ice.
Jurkat cells were fixed before or after digitonin lysis by rapidly injecting the cell suspension into $10 \mathrm{ml}$ of $2 \%$ paraformaldehyde (PFA, diluted in PBS (pH 7.4)) to avoid clumping. Following $10 \mathrm{~min}$ incubation at room temperature, the cells were washed in medium without serum. Quantification of apoptosis and necrosis was routinely performed by staining with a mixture of the cell-permeant chromatin dye $\mathrm{H}-33342$ (blue, $0.5 \mu \mathrm{g} / \mathrm{ml}$ ) and the membrane-impermeant dye SYTOX (green, $0.5 \mu \mathrm{M}$ ). ${ }^{21}$

\section{Phagocytosis assay}

Phagocytosis assays were performed as previously described. ${ }^{13}$ In brief, phagocytic cells (HMDM or BV-2) were stained with Dil $(2.5 \mu \mathrm{g} / \mathrm{ml}, 1 \mathrm{~h})$ to visualize cell bodies. Treated or untreated Jurkat cells were prelabeled with Fast Blue $(1 \mu \mathrm{g} / \mathrm{ml}, 5 \mathrm{~h})$ and added to macrophages at a ratio of 10 (target): 1 , and phagocytosis was allowed to proceed for $1 \mathrm{~h}$ at $37^{\circ} \mathrm{C}$. Nonphagocytosed target cells were then removed by 3-5 extensive washing steps in PBS. Ingested cells were counted by their blue (Fast Blue) fluorescence in 3-4 microscopic fields containing 40-80 phagocytes each. Phagocytic index was calculated by multiplying the percentage of phagocytosing cells with the average of ingested cells per phagocyte.

In addition, for confocal imaging of phagocytosis assays, special cell culture plates were developed. Since macrophages require plastic surfaces for their differentiation in vitro, they were seeded on 48-well plates. Following phagocytosis, cells were fixed in 4\% PFA (diluted in PBS (pH 7.2)) and the bottom of the wells was punched out from the plates, subsequently placed upside-down on a thin coverslip and monitored by confocal imaging through the glass coverslip.

\section{Production of liposomes}

PS and PC were obtained in chloroform at a concentration of $10 \mathrm{mg} / \mathrm{ml}$. For PS-liposomes, a solution of $70 \mathrm{~mol} \% \mathrm{PC}$ and $30 \mathrm{~mol} \%$ PS was prepared, whereas PC-liposomes consisted of pure PC. Chloroform $(250 \mu \mathrm{l})$ was evaporated under a nitrogen stream for $10 \mathrm{~min}$. The remaining lipid layers were subsequently dried in a vacuum for $12 \mathrm{~h}$ to remove chloroform remainders completely. The lipids were resuspended in $250 \mu \mathrm{l} \mathrm{PBS}$ at $75^{\circ} \mathrm{C}$ and total lipid concentration was adjusted to $13.2 \mathrm{mM}$. Following incubation at $75^{\circ} \mathrm{C}$ for $5 \mathrm{~h}$ under vigorous shaking, the lipid suspensions were sonicated at lowest energy with 1 pulse/s until the solution was clear. The liposomes were stored at $37^{\circ} \mathrm{C}$ for up to 1 week and used at a final concentration of $425 \mu \mathrm{M}$ lipid.

\section{Time-lapse microscopy}

BV-2 were grown in four-well dishes (Greiner) to $40 \%$ confluence. For experiments, serum-free RPMI medium supplemented with $40 \mathrm{mM}$ Hepes was used, and the culture dishes were equipped with a needle thermosensor and mounted on an electronically controlled heating block fixed on a microscope stage $\left(35 \pm 0.3^{\circ} \mathrm{C}\right)$. Images were recorded by $40 \times$ Varell contrast microscopy (Axiovert-25, ZEISS) at 20-s intervals for $480 \mathrm{~min}$ at a resolution of $768 \times 576$ pixels. The processed video sequences correspond to the pictures shown in Figure 5 . The number of video frames was reduced to a total of 200 for all sequences during the transformation into AVI format, and the replay speed is 30 frames/s, with every second corresponding to $30 \mathrm{~min}$ in real time.

\section{PS-surface exposure by MACS}

Following toxic challenge, $4 \times 10^{6}$ Jurkat cells were centrifuged and resuspended in $100 \mu \mathrm{l}$ annexin buffer containing biotin-linked annexin $\mathrm{V}$ 
$(1: 30)$ and incubated for $10 \mathrm{~min}$ at $25^{\circ} \mathrm{C}$. The cell suspension was then centrifuged, resuspended in $150 \mu \mathrm{l}$ annexin buffer containing streptavidincoated magnet beads $(5 \mathrm{mg} / \mathrm{ml})$, transferred to a $1.5 \mathrm{ml}$ reaction tube and incubated for $15 \mathrm{~min}$ at $25^{\circ} \mathrm{C}$. The tube was subsequently placed into a horizontal magnetic field using a magnetic particle concentrator (Dynal ${ }^{\mathbb{R}}$ MPC-S). Following $5 \mathrm{~min}$ incubation at $25^{\circ} \mathrm{C}$, the cell suspension was carefully transferred to a separate tube, while the cells that adhered to the magnetic surface were resuspended in annexin buffer. The two fractions were subsequently counted in a hemocytometer and the percentage of magnetically labeled (i.e. PS-surface-positive) cells was evaluated. For validation of the method, magnetic beads were reacted with (a) control cells, (b) ionomycin cells (intact plasma membrane, PS-positive), (c) apoptotic cells, late (lysed), (d) apoptotic cells and (e) necrotic cells (plasma membrane permeabilized for SYTOX or calcein). Cell pools were then analyzed by MACS and in parallel by microscopy. MACS showed PSpositive cells for $\mathrm{b} / \mathrm{c} / \mathrm{d} / \mathrm{e}$. A total of 200 cells for each condition were scored under the microscope. Data correlated $>90 \%$ with MACS, and in none of all the scored cells was a magnetic bead observed at the inside of the plasma membrane. The experiment was repeated with $1 \mu \mathrm{m}$ beads instead of the $2.8 \mu \mathrm{m}$ beads. A total of 10 cells each were carefully scanned on the confocal microscope, and even here we never observed a bead inside a cell.

\section{TNF $\alpha$ measurements}

HMDM were cultured on 96-well plates (Primaria ${ }^{\circledR}$ ) at an initial density of $0.8 \times 10^{5}$ cells/well. Following 1 week in culture, the medium was replaced by RPMI without serum. Jurkat cells were added to macrophages at a ratio of 5 (target cells): 1 in serum-free medium, and removed following $2 \mathrm{~h}$ of incubation at $37^{\circ} \mathrm{C}$. E. coli particles were vigorously mixed and sonicated before they were added to HMDM. Following $17 \mathrm{~h}$ incubation at $37^{\circ} \mathrm{C}$, supernatants were taken and stored at $-80^{\circ} \mathrm{C}$ until analysis of TNF $\alpha$ contents. TNF $\alpha$ was measured by sandwich ELISA (Pierce, Rockford, IL, USA).

\section{Statistical analysis}

Phagocytosis experiments were run in quadruplicates and repeated in at least three cell preparations. Critical experiments were scored by an investigator blinded for the experiments. Statistical significance was evaluated from the original data using the Student's $t$-test. The Welch test was applied when variances were not homogeneous within the compared groups. A $P$-value of less than 0.05 was considered to be significant.

\section{Acknowledgements}

We thank Dr. Armin Hatzelmann (Altana Pharma, Konstanz, Germany) for human monocytes and stimulating discussions, and Melanie Schwöbel, Pascal Renner and Andreas Rassov for excellent technical assistance. This work was supported by Deutsche Forschungsgemeinschaft (DFG) Grant We 686/18 and the University of Konstanz, AFF Grant 27/99.

\section{References}

1. Reddien PW, Cameron S and Horvitz HR (2001) Phagocytosis promotes programmed cell death in $C$. elegans. Nature 412: 198-202

2. Fadok VA and Chimini $G$ (2001) The phagocytosis of apoptotic cells. Semin. Immunol. 13: 365-372
3. Leist M and Jaattela M (2001) Four deaths and a funeral: from caspases to alternative mechanisms. Nat. Rev. Mol. Cell Biol. 2: 589-598

4. Wyllie AH, Kerr JF and Currie AR (1980) Cell death: the significance of apoptosis. Int. Rev. Cytol. 68: 251-306

5. Kerr JF, Wyllie AH and Currie AR (1972) Apoptosis: a basic biological phenomenon with wide-ranging implications in tissue kinetics. Br. J. Cancer 26: 239-257

6. Savill J (1997) Recognition and phagocytosis of cells undergoing apoptosis. $\mathrm{Br}$. Med. Bull. 53: 491-508

7. Hamon Y, Broccardo C, Chambenoit O, Luciani MF, Toti F, Chaslin S, Freyssinet JM, Devaux PF, McNeish J, Marguet D and Chimini G (2000) ABC1 promotes engulfment of apoptotic cells and transbilayer redistribution of phosphatidylserine. Nat. Cell Biol. 2: 399-406

8. Zhou Q, Zhao J, Stout JG, Luhm RA, Wiedmer T and Sims PJ (1997) Molecular cloning of human plasma membrane phospholipid scramblase. A protein mediating transbilayer movement of plasma membrane phospholipids. J. Biol. Chem. 272: 18240-18244

9. Devitt A, Pierce S, Oldreive C, Shingler WH and Gregory CD (2003) CD14dependent clearance of apoptotic cells by human macrophages: the role of phosphatidylserine. Cell Death Differ. 10: 371-382

10. Fadok VA, Bratton DL, Rose DM, Pearson A, Ezekewitz RA and Henson PM (2000) A receptor for phosphatidylserine-specific clearance of apoptotic cells [see comments]. Nature 405: 85-90

11. Fadok VA, Bratton DL, Konowal A, Freed PW, Westcott JY and Henson PM (1998) Macrophages that have ingested apoptotic cells in vitro inhibit proinflammatory cytokine production through autocrine/paracrine mechanisms involving TGF-beta, PGE2, and PAF. J. Clin. Invest. 101: 890898

12. Ren $Y$ and Savill J (1995) Proinflammatory cytokines potentiate thrombospondin-mediated phagocytosis of neutrophils undergoing apoptosis. J. Immunol. 154: 2366-2374

13. Hirt UA, Gantner F and Leist M (2000) Phagocytosis of nonapoptotic cells dying by caspase-independent mechanisms [In Process Citation]. J. Immunol. 164: 6520-6529

14. Volbracht C, Leist M, Kolb SA and Nicotera P (2001) Apoptosis in caspaseinhibited neurons. Mol. Med. 7: 36-48

15. Foghsgaard L, Wissing D, Mauch D, Lademann U, Bastholm L, Boes M, Elling F, Leist M and Jaattela M (2001) Cathepsin B acts as a dominant execution protease in tumor cell apoptosis induced by tumor necrosis factor. J. Cell Biol. 153: $999-1010$

16. Leist M and Nicotera P (1997) The shape of cell death. Biochem. Biophys. Res. Commun. 236: 1-9

17. Yu SW, Wang H, Poitras MF, Coombs C, Bowers WJ, Federoff HJ, Poirier GG, Dawson TM and Dawson VL (2002) Mediation of poly(ADP-ribose) polymerase-1-dependent cell death by apoptosis-inducing factor. Science 297: 259-263

18. Holler N, Zaru R, Micheau O, Thome M, Attinger A, Valitutti S, Bodmer JL, Schneider P, Seed B and Tschopp J (2000) Fas triggers an alternative, caspase-8-independent cell death pathway using the kinase RIP as effector molecule. Nat. Immunol. 1: 489-495

19. Kane DJ, Ord T, Anton R and Bredesen DE (1995) Expression of bcl-2 inhibits necrotic neural cell death. J. Neurosci. Res. 40: 269-275

20. Single B, Leist M and Nicotera $P$ (2001) Differential effects of bcl-2 on cell death triggered under ATP- depleting conditions. Exp. Cell Res. 262: 8-16

21. Leist M, Single B, Castoldi AF, Kuhnle S and Nicotera P (1997) Intracellular adenosine triphosphate (ATP) concentration: a switch in the decision between apoptosis and necrosis. J. Exp. Med. 185: 1481-1486

22. Leist M, Single B, Naumann H, Fava E, Simon B, Kuhnle $S$ and Nicotera $P$ (1999) Inhibition of mitochondrial ATP generation by nitric oxide switches apoptosis to necrosis. Exp. Cell Res. 249: 396-403

23. Hirsch T, Marchetti P, Susin SA, Dallaporta B, Zamzami N, Marzo I, Geuskens $M$ and Kroemer $G$ (1997) The apoptosis-necrosis paradox. Apoptogenic proteases activated after mitochondrial permeability transition determine the mode of cell death. Oncogene 15: 1573-1581

24. Nylandsted J, Wick W, Hirt UA, Brand K, Rohde M, Leist M, Weller M and Jaattela M (2002) Eradication of glioblastoma, and breast and colon carcinoma xenografts by Hsp70 depletion. Cancer Res. 62: 7139-7142

25. Voll RE, Herrmann M, Roth EA, Stach C, Kalden JR and Girkontaite I (1997) Immunosuppressive effects of apoptotic cells. Nature 390: 350-351 
26. Asea A, Kraeft SK, Kurt-Jones EA, Stevenson MA, Chen LB, Finberg RW, Koo GC and Calderwood SK (2000) HSP70 stimulates cytokine production through a CD14-dependant pathway, demonstrating its dual role as a chaperone and cytokine. Nat. Med. 6: 435-442

27. Henson PM, Bratton DL and Fadok VA (2001) The phosphatidylserine receptor: a crucial molecular switch? Nat. Rev. Mol. Cell Biol. 2: 627-633

28. Repa JJ and Mangelsdorf DJ (2002) The liver $X$ receptor gene team: potential new players in atherosclerosis. Nat. Med. 8: 1243-1248

29. Chung S, Gumienny TL, Hengartner MO and Driscoll M (2000) A common set of engulfment genes mediates removal of both apoptotic and necrotic cell corpses in C. elegans. Nat. Cell Biol. 2: 931-937

30. Fadok VA, Warner ML, Bratton DL and Henson PM (1998) CD36 is required for phagocytosis of apoptotic cells by human macrophages that use either a phosphatidylserine receptor or the vitronectin receptor (alpha $v$ beta 3 ). J. Immunol. 161: 6250-6257

31. Pradhan D, Krahling S, Williamson P and Schlegel RA (1997) Multiple systems for recognition of apoptotic lymphocytes by macrophages. Mol. Biol. Cell. 8 : 767-778

32. Rubartelli A, Poggi A and Zocchi MR (1997) The selective engulfment of apoptotic bodies by dendritic cells is mediated by the alpha(v)beta3 integrin and requires intracellular and extracellular calcium. Eur. J. Immunol. 27: 1893-1900

33. Hampton MB, Vanags DM, Porn-Ares MI and Orrenius S (1996) Involvement of extracellular calcium in phosphatidylserine exposure during apoptosis. FEBS Lett. 399: 277-282

34. Single B, Leist M and Nicotera $P$ (1998) Simultaneous release of adenylate kinase and cytochrome $c$ in cell death [letter]. Cell Death Differ. 5: 1001-1003

35. Freire-de-Lima CG, Nascimento DO, Soares MB, Bozza PT, Castro-Faria-Neto HC, de Mello FG, DosReis GA and Lopes MF (2000) Uptake of apoptotic cells drives the growth of a pathogenic trypanosome in macrophages. Nature 403: 199-203

36. Fadok VA, Bratton DL, Guthrie L and Henson PM (2001) Differential effects of apoptotic versus lysed cells on macrophage production of cytokines: role of proteases. J. Immunol. 166: 6847-6854

37. Chautan M, Chazal G, Cecconi F, Gruss P and Golstein P (1999) Interdigital cell death can occur through a necrotic and caspase-independent. Curr. Biol. 9: 967-970

38. Shacter E, Williams JA, Hinson RM, Senturker S and Lee YJ (2000) Oxidative stress interferes with cancer chemotherapy: inhibition of lymphoma cell apoptosis and phagocytosis. Blood 96: 307-313
39. Henson PM, Bratton DL and Fadok VA (2001) OPINION The phosphatidylserine receptor: a crucial molecular switch? Nat. Rev. Mol. Cell Biol. 2: 627-633

40. Guzhova IV, Arnholdt AC, Darieva ZA, Kinev AV, Lasunskaia EB, Nilsson K, Bozhkov VM, Voronin AP and Margulis BA (1998) Effects of exogenous stress protein 70 on the functional properties of human promonocytes through binding to cell surface and internalization. Cell Stress Chaperones 3: 67-77

41. Kagan VE, Gleiss B, Tyurina YY, Tyurin VA, Elenstrom-Magnusson C, Liu SX, Serinkan FB, Arroyo A, Chandra J, Orrenius S and Fadeel B (2002) A role for oxidative stress in apoptosis: oxidation and externalization of phosphatidylserine is required for macrophage clearance of cells undergoing fas-mediated apoptosis. J. Immunol. 169: 487-499

42. Cocco RE and Ucker DS (2001) Distinct modes of macrophage recognition for apoptotic and necrotic cells are not specified exclusively by phosphatidylserine exposure. Mol. Biol. Cell 12: 919-930

43. Bratton DL, Fadok VA, Richter DA, Kailey JM, Guthrie LA and Henson PM (1997) Appearance of phosphatidylserine on apoptotic cells requires calciummediated nonspecific flip-flop and is enhanced by loss of the aminophospholipid translocase. J. Biol. Chem. 272: 26159-26165

44. Verhoven B, Schlegel RA and Williamson P (1995) Mechanisms of phosphatidylserine exposure, a phagocyte recognition signal, on apoptotic $T$ lymphocytes. J. Exp. Med. 182: 1597-1601

45. Volbracht C, Leist M and Nicotera P (1999) ATP controls neuronal apoptosis triggered by microtubule breakdown or potassium deprivation. Mol. Med. 5 : 477-489

46. Hoeppner DJ, Hengartner MO and Schnabel R (2001) Engulfment genes cooperate with ced-3 to promote cell death in Caenorhabditis elegans. Nature 412: 202-206

47. Verhoven B, Krahling S, Schlegel RA and Williamson P (1999) Regulation of phosphatidylserine exposure and phagocytosis of apoptotic $T$ lymphocytes. Cell Death Differ. 6: 262-270

48. Fladmark KE, Brustugun OT, Hovland R, Boe R, Gjertsen BT, Zhivotovsky B and Doskeland SO (1999) Ultrarapid caspase-3 dependent apoptosis induction by serine/threonine phosphatase inhibitors. Cell Death Differ. 6: 1099-1108

49. Blasi E, Barluzzi R, Bocchini V, Mazzolla R and Bistoni F (1990) Immortalization of murine microglial cells by a v-raf/v-myc carrying retrovirus. J. Neuroimmunol. 27: 229-237 